\title{
GREEN TEA AS A TREATMENT MODALITY FOR DENTINAL EROSION
}

\section{KANAV JAIN \& PADMANIDHI AGARWAL}

Department of Dentistry, All India Institute of Medical Sciences (AIIMS), Rishikesh, India

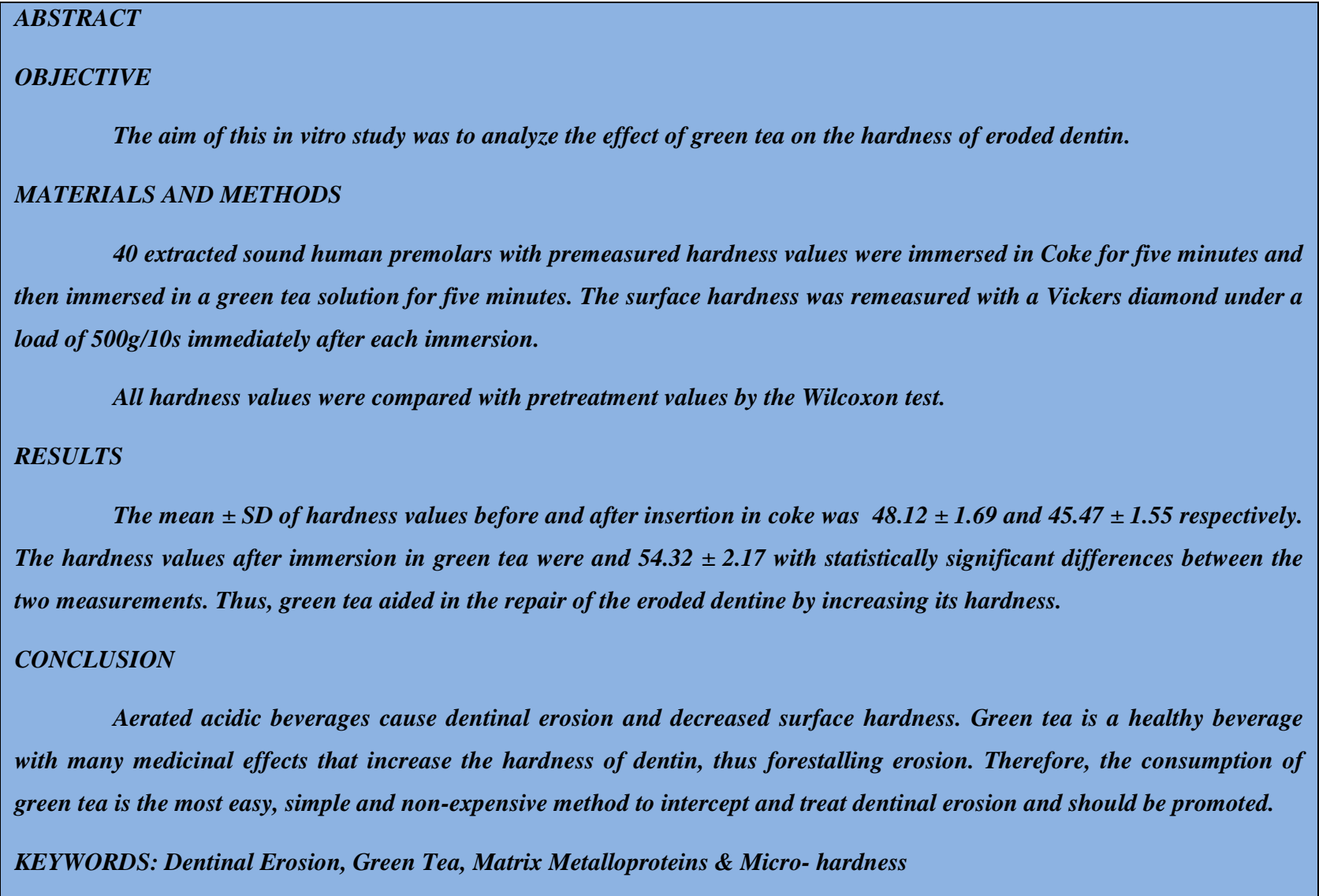

Received: Jan 18, 2018; Accepted: Feb 07, 2018; Published: Mar 20, 2018; Paper Id.: IJDRDJUN20183

\section{INTRODUCTION}

Gradational loss of tooth structure is a physiological process that transpires throughout life. It is usually slow and goes undetected for years, rarely problematic for the patient. Increased destruction, however, is considered pathological, and can manifest as attrition, abrasion, erosion, and abfraction. It can cause sensitivity while impeding the normal functioning and aesthetics.

Erosion refers to the loss of tooth structure by chemical or electrochemical means that does not involve bacteria. Itcan affect any gender or age group and is accepted to be the most common cause of tooth wear. ${ }^{2}$ Oneimportant extrinsic cause of erosion is the escalated consumption of acidic drinks and foodstuffs. In recent times, changes in lifestyle and eating habits with a drastic increase in frequency and quantity of acidic product intake has cascaded an increase in erosion. ${ }^{3}$ Erosive tooth demineralization is characterized by initial softening of the enamel surface followed by successional dissolution of enamel crystal layers, leading to permanent loss of tooth structure. ${ }^{4}$ This organic degradation is also a consequence of matrix metalloproteinases(MMPs). These are present in saliva, gingival 
crevicular fluid, and dental hard tissues and cause the destruction of the collagen matrix of dentin. ${ }^{5}$

Knowledge regarding the etiology of dental erosion is expansive but no typically accepted preventive methods subsist. It has been widely shown that some chemical agents have anti-erosive potential. As the maintenance of the organic matrix is desirable to decrease the progression of erosion, it seems worth to analyze the effect the of application of MMPinhibitors. A commonly consumed, a natural beverage such as green tea (Camellia sinensis) has lately gained much attention. It has been used for centuries as a therapeutic agent and is rich in polyphenols, which have distinct inhibitory activity against MMPs. ${ }^{6}$ The aim of this study was to investigate, the effect of green tea in vitro, on eroded dentin by measuring tooth hardness values.

\section{MATERIAL AND METHODS}

Forty extracted human premolars were used for this study. Teeth extracted for orthodontic or periodontic reasons were included while teeth with hypocalcifications, developmental defects, any restorations or cracks were excluded. Teeth were cleaned with ultrasonic scalers and reexamined under a microscope for any cracks or caries. The teeth that did not meet the inclusion criteria were excluded from the study. Enamel was stripped from the buccal surface of the teeth with the help of a cutting disk with water spray to expose the dentin. The teeth were then embedded in dental stone and ground flat with sandpaper(Figure 1a,1b). No ethical clearance was obtained as this was an in vitro study.

The micro hardness of the teeth was measured. The hardness was measured using the Vickers hardness tester (Model VM 50, Fuel Instruments \& Engineers Ltd, Maharashtra) under a load of 500g for 10 seconds (Figure 1c). Three indentations were made on the cervical third of each specimen. The specimens were then immersed in Coke ( $\mathrm{pH} 2.8)$ for 5 minutes at 15 degrees following which the hardness was measured.

Green tea leaves were obtained from Dibrugarh District, Assam. 100gm of the leaves were dried, ground \& softened with ethanol: water 70:30. The extract was then dried and stored in the refrigerator for further use. Two grams of the prepared green tea extract were introduced into $180 \mathrm{ml}$ of boiled water. The samples were then immersed in the hot green tea solution $(\mathrm{pH} 7)$ for 5 minutes at 80 degrees. The hardness values were measured in the cervical third of each tooth with three indentations in each specimen.

The average hardness values before and after each treatment were calculated and compared with Wilcoxon test. Statistical Package for the Social Sciences (SPSS version 16, IBM, Chicago, IL, USA) was used for all analyses and a p value $\leq 0.05$ was considered statistically significant.

\section{RESULTS}

The mean hardness value $\left(\mathrm{Kg}\right.$ force $\left./ \mathrm{mm}^{2}\right)$ of teeth before immersion in coke was. $48.12 \pm 1.69$ The maximum value was 52.88 while the minimum value was 45.52 . There was a significant decrease in the microhardness after immersion in coke with the mean \pm SD hardness value after immersing teeth in coke was $45.475 \pm 1.55$ with the maximum range being 48.96 and the minimum being 42.37. Following immersion of the eroded teeth in green tea solution, the hardness value was $54.32 \pm 2.17$. The maximum range was 58.19 and the minimum range was 53.48(Table 1).Wilcoxon test revealed statistically significant differences between the two groups $(\mathrm{p}<0.05)$. 


\section{DISCUSSIONS}

Dental erosion is not a simple process. After acidic soft drink consumption, there is mineral dissolution and exposure of the collagen. Erosion in enamel starts with the partial loss of surface mineral resulting in an increase in roughness. ${ }^{7}$ If the acid impact continues, the bulk mineral loss occurs. The surface structure of eroded enamel resembles a typical etching pattern. This partial loss of mineral at the surface results in softening of the enamel and makes eroded enamel surfaces vulnerable to physical damage. After prolonged or severe erosion has caused loss of volume from the tooth surface, a softened layer persists at the surface of the remaining tissue. ${ }^{8}$

When dentin is exposed to acids at the clinically high strength and concentration, the mineral component readily dissolves while the organic portion is retained. Even after a 30-second immersion in low pH citric acid, a thin zone of a dense, fibrous collagen network develops. ${ }^{9}$ This zone increases depending on the demineralization agent and exposure time. A fully demineralized zone develops, beneath which partially demineralized dentin is found, and finally sound dentin is reached. ${ }^{10}$ The partially demineralized zone, however, is not always present. Initially, both peri- and intertubular dentin recede at similar rates, but after the first minute, the peritubular dentin is further dissolved while the intertubular region appears more stable.

The hardness of human tooth has been determined by a variety of methods, including abrasion, scratch, and indentation techniques. The micro-scratch or micro-indentation methods are preferred and Knoops and Vickers diamond indenter are most frequently used. The Vickers hardness tester consists of a small diamond square- based pyramid with which the indentation is made using an arbitrary amount of force. The indentation is then enlarged and measured. A force of $500 \mathrm{~g}$ was used in this study. ${ }^{11}$

Characteristics of a beverage like its taste, temperature, and fragrance, determine the volume and frequency of intake. The drinking habit rather than the content of the drink is more critical to dental erosion. ${ }^{12}$ Patients with erosion have been reported to drink more carbonated drinks, drinking from a can and drinking faster than the controls. The $\mathrm{pH}$ remained lower for a longer duration in them. ${ }^{13,14}$ Coke is a carbonated drink that is widely consumed worldwide. It is acidic and has a detrimental effect on the hardness of teeth. ${ }^{13}$ Even in our study, hardness values of dentin were decreased significantly after consumption of the acidic beverage. Test results showed that after immersion on teeth in coke for 5 minutes the mean hardness decreased from 49.64 to 45.02 .0 which is in accordance with previous studies. ${ }^{15}$

Tea is the most popular beverage in the world after water. In the last couple of years, there is a growing interest in green tea in the western world due to scientific findings that show the health potentials of the beverage. ${ }^{16}$ It is derived from a plant Camellia sinensis which grows mainly in China and in Southeast Asia. Green tea has a unique composition of polyphenols, mainly catechins (flavanols). The four principal catechins are epigallocatechingallate (EGCG-59\%), epigallocatechin(EGC-19\%), epicatechingallate(ECG-13.6\%) and epicatechin (EC-6.4\%). ${ }^{16,17}$

MMPs is present in both dentin and saliva and play an important role in the dentin erosion progression. MMPs are cell-derived proteolytic enzyme family with 26 identified members which can function beneficially during tissue remodeling and during formation mineralization of dentin. ${ }^{18}$ These are secreted from fibroblasts, osteoblasts, and odontoblastsas zymogens(an inactive enzyme form) and are bound in the dentin during formation. They can be catalyzed by active enzymes after their release from dentin or due to a decrease in $\mathrm{pH}$ of 4.5 or below, like in carious lesions or after consumption of acidic drinks. ${ }^{19,20}$ 
Recent evidence from in vitro and in situ studies has shown a protective role of MMP inhibitors against dentin erosion and erosion plus abrasion. ${ }^{21}$ Thus, green tea, an MMP inhibitor, was used to study the effect of dental erosion. The increase in surface microhardness values after immersion in green tea solution reveals an improvement in the demineralized structure of eroded dentin. ${ }^{22}$ After immersion in green tea, there are obvious deposits on the dentin surface and conversion into a more organized, feature is detected on SEM evaluation. ${ }^{2}$ Preservation of dentin matrix by MMP inhibition might be another probable explanation for these observations. Limitations of this study include a small sample size and its in vitro nature. Probably more studies in this will reveal further detailed results on the improvement in the hardness of degenerating teeth.

\section{CONCLUSIONS}

Erosion the most common cause of tooth wear which can majorly be contributed to the increased consumption of acidic foods and drinks. Green tea is rich in polyphenols, a potent MMP inhibitor and thus a suitable solution which not only prevents enamel softening but also induces hardening of the tooth surface following tooth wear. The consumption of green tea should be encouraged for its many benefits and its effects further studied.

\section{Conflict of Interest: None}

Funding: No external Source of funding

\section{REFERENCES}

1. Larsen MJ, Nyvad B. Enamel erosion by some soft drinks and orange juices relative to their pH, buffering effects and contents of calcium phosphate. Caries Res. 1999;33(1):81-87.

2. Mirkarimi M, Toomarian L. Effect of green tea extract on the treatment of dentin erosion: an in vitro study. J Dent (Tehran). 2012 Fall;9(4):224-8.

3. Packer CD: Cola-induced hypokalaemia: a super- sized problem. Int J ClinPract 2009; 63:833-835.

4. Lussi A. Erosive tooth wear a multifactorial condition of growing concern and increasing knowledge. Monogr Oral Sci. $2006 ; 20: 1-8$.

5. Mäkelä M, Salo T, Uitto VJ, Larjava H. Matrix metalloproteinases (MMP-2 and MMP-9) of the oral cavity: cellular origin and relationship to periodontal status. J Dent Res. 1994 Aug;73(8)

6. Kato MT, Magalhães AC, Rios D, Hannas AR, Attin T, Buzalaf MA. Protective effect of green tea on dentin erosion and abrasion. J Appl Oral Sci. 2009 Nov-Dec;17(6):560-4.

7. Nekrashevych Y, Stösser L: Protective influence of experimentally formed salivary pellicle on enamel erosion. An in vitro study. Caries Res 2003; 37: 225-231

8. Carvalho TS, Baumann T, Lussi A. Does erosion progress differently on teeth already presenting clinical signs of erosive tooth wear than on sound teeth? An in vitro pilot trial. BMC Oral Health. 2016 Jul 7;17(1):14.

9. Breschi L, Gobbi P, Mazzotti G, Falconi M, Ellis TH, Stangel I. High resolution SEM evaluation of dentin etched with maleic and citric acid. Dent Mater. 2002 Jan;18(1):26-35.

10. Kinney JH, Balooch M, Haupt DL Jr, Marshall SJ, Marshall GWJ: Mineral distribution and dimensional changes in human dentin during demineralisation. J Dent Res 1995; 74:1179-1184. 
11. R. L. Smith \& G. E. Sandland, "An Accurate Method of Determining the Hardness of Metals, with Particular Reference to Those of a High Degree of Hardness," Proceedings of the Institution of Mechanical Engineers, Vol. I, 1922, p 623-641.

12. Coombes JS. Sports drinks and dental erosion. Am J Dent. 2005 Apr;18(2):101-4.

13. Murray B, Moss SJ. Sports drinks and tooth decay. J Am Dent Assoc1997; 128: 1200, 1202, 1204.

14. Moss SJ. Dental erosion. Int Dent J 1998; 48: 529-539.

15. Murrell S, Marshall TA, Moynihan PJ, Qian F, Wefel JS. Comparison of in vitro erosion potentials between beverages available in the United Kingdom and the United States. J Dent. 2010 Apr;38(4):284-9.

16. Chacko et al.: Beneficial effects of green tea: A literature review. Chinese Medicine 2010 5:13. McKay DL, Blumberg JB. The role of tea in human health: an update. J Am CollNutr. 2002;21:1-13.

17. Koo MW, Cho CH. Pharmacological effects of green tea on the gastrointestinal system. Eur J Pharmacol. 2004 Oct 1;500(1$3): 177-85$.

18. Hannas AR, Pereira JC, Granjeiro JM, Tjäderhane L. The role of matrix metalloproteinases in the oral environment. ActaOdontol Scand. 2007 Feb;65(1):1-13.

19. Moon PC, Weaver J, Brooks CN. Review of matrix metalloproteinases' effect on the hybrid dentin bond layer stability and chlorhexidine clinical use to prevent bond failure. Open Dent J. $2010 \mathrm{Jul}$ 20;4:147-52.

20. Mazzoni A, Mannello F, Tay FR, et al. Zymographic analysis and characterization of MMP-2 and -9 forms in human sound dentin. J Dent Res. 2007;86(5):436-40.

21. Buzalaf MA, Kato MT, Hannas AR. The role of matrix metalloproteinases in dental erosion. Adv Dent Res. 2012 Sep;24(2):726.

22. De Moraes MD, Carneiro JR, Passos VF, Santiago SL. Effect of green tea as a protective measure against dental erosion in coronary dentine. Braz Oral Res. 2016;30.

\section{FIGURE LEGENDS}

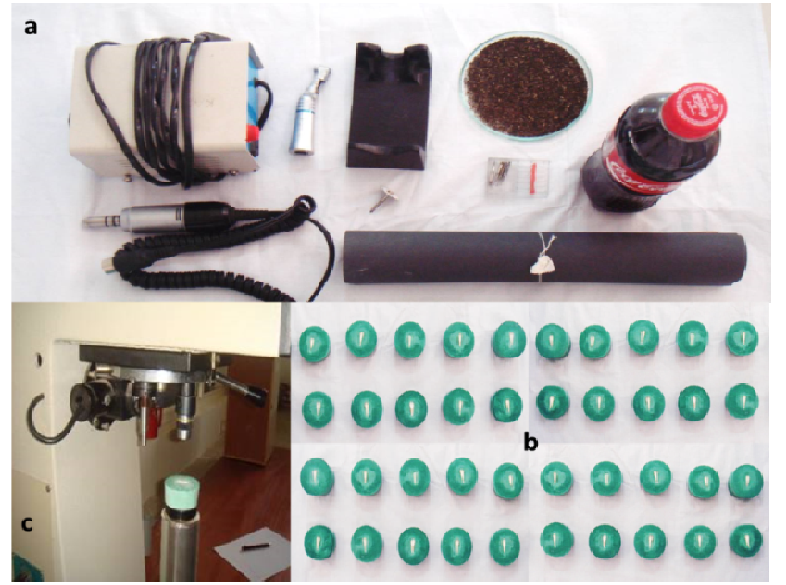

Figure 1: Material and Methods

(a) Armamentarium (b) Mounted and Sectioned Specimens (c) Vickers Hardness Test 
